\title{
Risk Assessment of Exposure to Trans Fat in Canada
}

\author{
Sara Krenosky ${ }^{1, *}$, Mary L'Abbé ${ }^{1}$, Nora Lee ${ }^{1}$, Lynne Underhill' ${ }^{1}$ \\ Michel Vigneault', Samuel Godefroy ${ }^{1}$ and Nimal Ratnayake ${ }^{1}$ \\ 1 Food Directorate, Health Products and Food Branch, Health Canada, Canada \\ * Corresponding author E-mail: sara.krenosky@hc-sc.gc.ca
}

Received 24 July 2012; final version received 19 October 2012

(C) 2012 Krenosky et al.; licensee InTech. This is an open access article distributed under the terms of the Creative Commons Attribution License (http://creativecommons.org/licenses/by/3.0), which permits unrestricted use, distribution, and reproduction in any medium, provided the original work is properly cited.

Abstract Trans fats are undesirable because they raise LDL-cholesterol and lower HDL-cholesterol levels in the blood, which can lead to an increased risk of coronary heart disease. In the mid-1990's, researchers estimated that Canadians had one of the highest average trans fat intakes in the world, estimated to be approximately $3.7 \%$ of energy. The World Health Organization recommends that average intakes of trans fats should be less than $1 \%$ of total energy. As such Canada has pursued a multi-faceted approach to decrease trans fat levels in Canadian foods. Initiatives undertaken include: mandatory nutrition labelling, the establishment of a multi-stakeholder Trans Fat Task Force to develop recommendations and strategies to eliminate trans fat in Canadian foods, and most recently the monitoring of industry's efforts in reducing trans fats from their food products. Collectively, these initiatives have proven successful as average trans fat intakes have been reduced to $1.42 \%$ of overall energy. Further reductions in trans fat levels in the Canadian food supply are needed to meet the target of $1 \%$ of energy, the associated public health objectives, and the protection of vulnerable populations.

Keywords Trans fat, Risk Assessment, Intakes, Food Supply, Monitoring

\section{Introduction}

The objectives of this paper are: 1) to summarize the findings from authoritative bodies on the health risks associated with trans fat intakes, 2) to describe the findings from monitoring trans fat levels in foods in Canada undertaken by Health Canada from 2005-2009 and the resulting estimates of trans fat intakes by Canadians, and 3) to characterize the health risks associated with such intakes.

\subsection{What is Trans Fat?}

Trans fat or trans fatty acids (TFAs) are chemically defined as unsaturated fatty acids containing a carboncarbon double bond in the fatty acid chain in the "trans" position (Figure 1) [1], [2].

As depicted in the illustration, in the "trans" configuration the hydrogen atoms are on opposite sides of the double bond resulting in a fatty acid chain that is straight [1], similar to saturated fats in that way. In contrast, when the hydrogen atoms are in the "cis" position, as in the case of oleic acid, they are on the same side of the double bond. This causes a bend or a kink in the fatty acid chain [1]. Straight chains are more easily 
compacted than bent chains and result in a less fluid material. Most natural unsaturated fatty acids are found in the cis position, including oleic acid, linoleic acid, $\alpha$ linolenic acid, and the marine fatty acids [2]. Partial hydrogenation converts many unsaturated double bonds from a cis- to a trans-configuration (called geometric isomerization). This process also often induces changes in the double bond position to a different carbon in the fatty acid chain (called positional isomerization) [2].
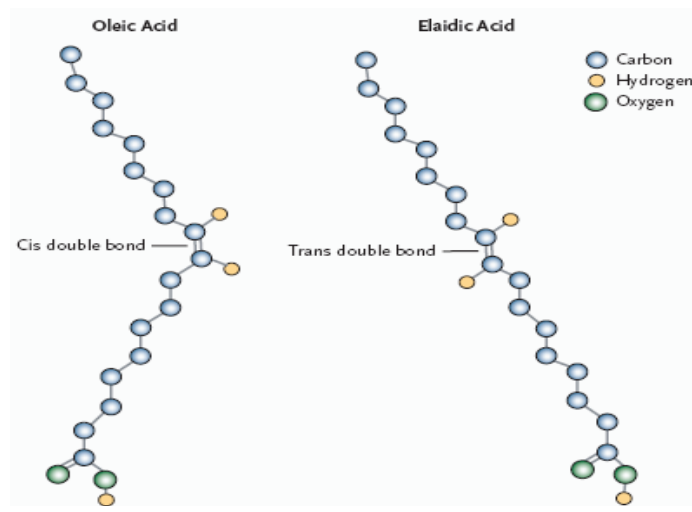

Figure 1. Structure of Cis and Trans Fatty Acids [1]

\subsection{Sources of Human Exposure to Trans Fat}

Trans fats are formed during the partial hydrogenation of unsaturated fat. Vegetable oils are hydrogenated to increase their melting point so that they are solid or semisolid at room temperature. Partially hydrogenated oils (PHO) are used to make shortenings and margarines for processing, baking, and frying. Generally, products made with PHOs have a longer shelf life than if made with liquid oils and are more stable and break down less easily under conditions of high temperature heating. Trans fats can also be found at low levels in fully hydrogenated oils and in refined oils [3].

Trans fats are also found naturally at relatively low levels, historically between $2-5 \%$ of the total fat content in ruminant-derived foods (for example, beef, dairy products, lamb) [4]. Recent data from Health Canada research indicated that TFA levels measured in some dairy products (cheese, butter, milk, and cream) range from $4.2 \%-7.4 \%$ of total fats [4]. The level of fat in these samples ranged from $10 \%$ (half-cream product) to $80 \%$ (salted butter) [4]. The highest levels were found in cheese and butter [4].

\section{Hazard Characterisation: Health Hazards of Trans Fat}

Trans fats are not essential, are not required for any specific body function, and provide no known benefit to human health. The adverse effects on heart health are well known [1], [2], [5]. Trans fat raises LDL-cholesterol (LDL-C) and lowers HDL-cholesterol (HDL-C) levels in the blood. Elevated levels of LDL-C and lowered levels of HDL-C are risk factors in the development of coronary heart disease (CHD). Dietary TFAs are considered to pose an even greater risk to health than saturated fats (SFAs) since SFAs raise both LDL-C and HDL-C levels [5]. Furthermore, evidence from both controlled trials and observational studies indicates that TFAs from partially hydrogenated sources adversely affects multiple cardiovascular disease risk factors, not only blood cholesterol profiles [5], [6], [7].

Health Canada has adopted the recommendations of the US-Canada Panel on Macronutrients of the U.S. National Academies' Institute of Medicine (IOM), published in 2002, with respect to intakes of trans fat [8]. Therefore, the hazard identification and characterization of TFAs upon which this risk assessment is based was done by this Panel. This was supplemented by reference to the work of the World Health Organization (WHO) [2], [9].

Based on their assessment of the evidence linking TFAs to coronary heart disease available at that time [10], [11], the IOM Panel recommended that TFA consumption be as low as possible while consuming a nutritionally adequate diet [5]. The IOM also noted that it would be difficult to lower trans fat intakes to $0 \%$ energy since a nutritionally adequate diet would contain some naturally occurring TFAs [5]. No Adequate Intake or Recommended Dietary Allowance was set for TFAs because they have no nutritional function. Also, no, Tolerable Upper Intake Level (UL) was set because any incremental increase in TFA intake was found to increase CHD risk [5]. The Panel also stated that because the intake of TFAs and LDL-C is a positive linear relationship, even very low intakes of TFAs may increase the risk of CHD [5]. It was determined that there was a dose-dependent relationship between TFAs and the LDL-C:HDL-C ratio when the results from nine randomized studies were combined and the magnitude of this effect was greater for TFAs than with SFAs [5], [11]. Furthermore, when there was a direct comparison in six of the trials, the effect of TFAs on the ratio of LDL-C to HDL-C was statistically significantly larger than that of SFAs [11]. It was concluded that these studies provided definitive evidence that TFAs raise this ratio more than do SFAs [5], [11].

Subsequently, in 2003, the World Health Organization (WHO) advised that diets should provide a very low intake of TFAs; that is, average intakes of TFAs should be less than $1 \%$ of total energy [9]. Given the uncertainty about whether health effects differ between naturally occurring TFAs and industrially produced TFAs and the analytical difficulty in distinguishing these, the WHO did not distinguish between these sources in making the $1 \%$ recommendation [6]. 
In November 2008, the Food and Agriculture Organization (FAO) and the WHO convened a meeting to review the major developments in the field of fatty acids in human nutrition. It was recognized by experts that the current recommendation, average trans fat intakes of less than $1 \%$ of total energy, may need to be revisited in light of the fact that it does not fully take into account the distribution of intakes [12]. Thus, the removal of partially hydrogenated fats and oils from the human food supply may be needed to protect certain groups from having dangerously high intakes [12].

In support of the expert consultation held in November 2008, a scientific update [6] which included the most recent data as well as earlier studies available on heart health effects of TFAs was published in the European Journal of Clinical Nutrition's Supplement entitled "WHO Scientific Update on trans fatty acids". This update considered evidence from both controlled and observational studies for the effects of trans fat consumption on CHD. The authors summarized the results of over twenty controlled studies and several meta-analyses (conducted in 2003 and 2006) focussing on the effects of TFAs on blood lipids and lipoproteins. The adverse effects of TFAs on LDL-C and HDL-C were clearly demonstrated: they increased LDL-C, decreased HDL-C, and increased the ratio of total-cholesterol to HDL-C [6]. The same authors report in a separate paper their own meta-analyses of 13 controlled trials conducted from 1982 until 2007. They report that for each 1\% energy replacement of TFAs with SFAs, monounsaturated fats (MUFAs) or polyunsaturated fats (PUFAs), the totalcholesterol:HDL-C ratio decreased by $0.31,0.54$ and 0.67 , respectively [7].

A limitation of these types of studies, acknowledged by the authors, is that they are generally short term, high dose, and in generally healthy individuals. Ethical concerns limit the possibility of longer term trials, when almost certain harm will occur in individuals subjected to a high trans fat intervention. The authors also reviewed observational studies examining the correlation between trans fat consumption and CHD, in both prospective and retrospective study designs. These types of studies have different limitations, such as difficulty in adjusting for confounding risk factors, reliance on dietary estimates, and change in dietary habits over time. Seven retrospective and five prospective studies were summarized. Five of the retrospective and four of the prospective studies showed a clear association between trans fat consumption and CHD events. A meta-analysis of just the four prospective cohort studies estimated a $17 \%, 21 \%$ and $24 \%$ lower risk of CHD for every $2 \%$ of energy from trans fat intake that is replaced with SFA, cis MUFA and cis PUFA, respectively [7].
The evidence from controlled trials or observational studies provide concordant data that consumption of trans fat from PHO adversely affects multiple cardiovascular risk factors and contributes significantly to increased risk of CHD.

\section{Exposure Assessment}

\subsection{Historical Intakes and Sources of TFAs in Canada}

In Canada, scientists raised concerns about the potential detrimental effects of TFAs and the levels in the Canadian diet as far back as the 1970s, recommending that the trans fat levels not increase [13], [14]. The evidence at the time was largely from animal studies and was inconclusive. However, the use of PHO continued to increase. Partially hydrogenated oils were attractive to the food industry in the manufacture of margarines, shortenings and the preparation of commercial baked products because of their better functional properties, longer shelf life, oxidative stability and semi-solidity [1], [2]. Also, they were promoted as an alternative to butter and other animal fats and tropical oils which were the fats most associated with having negative health attributes at that time. By the mid-1990's, researchers estimated that Canadians had one of the highest average trans fat intakes in the world, estimated to be approximately $8.4 \mathrm{~g} /$ day or $3.7 \%$ of energy [15]. This estimate was made using both dietary intake data and analysis of human milk samples. Foods that were contributing to the high trans fat intakes included crackers, margarines, shortenings, donuts, cookies, pie shells, breaded chicken, cake mixes and cakes, french fries, sauces, and gravies [16], [17]. Detailed fat analysis of over 200 locally and nationally available foods indicated that the TFA levels in some foods reached as high as $50-56 \%$ TFA as percent of total fat [16]. The variability of TFA levels in certain food categories was quite large as well [16]. In light of one of the highest intakes of trans fat in the world, Canada became the first country in the world to require the declaration of trans fat in nutrition labelling. The regulations requiring the mandatory declaration of trans fat were promulgated in December 2002 and came into effect for most prepackaged foods in December 2005 [18].

The availability of trans fat information on the Nutrition Facts table helped draw the attention of consumers and public health professionals to the presence of TFAs in prepackaged foods, which resulted in a significant reduction of the trans fat content of these foods [19], [20], [21]. However, there was also interest expressed by Canadian health organizations that more actions were needed to ensure that trans fat levels were reduced across the food supply. 
Therefore, in light of this increased interest and in response to other factors [22], in 2005, a multi-stakeholder task force was established to study trans fat in the Canadian food supply. The mandate and the final report of the Trans Fat Task Force (TFTF), "TRANSforming the Food Supply", were published on Health Canada's website [23].

Among the analyses conducted for the Task Force in 2005 was a new estimate of trans fat intake. Trans fat composition values and intakes were obtained from the Canadian Nutrient File (CNF) archived records, from the Nutrition Survey System (NSS) databases used during this time period, as well as data files from three Provincial nutrition surveys. The analyses indicated that average intakes of TFAs by Canadians in 2005 had decreased to $4.4 \mathrm{~g} /$ day from the previous high of $8.4 \mathrm{~g} /$ day as of 1995 [24]. This level was, nevertheless, still well above the WHO recommendation of less than $1 \%$ of overall energy intake (approximately $2.2 \mathrm{~g} /$ day).

In response to the TFTF's final report, which called for a regulatory approach to limit the levels of TFA in the Canadian food supply [23], in June 2007, it was announced that the food industry would have two years to achieve, on a voluntary basis, limits of $2 \%$ of total fat content for vegetable oils and soft, spreadable margarines and $5 \%$ of total fat content for all other foods [25]. Additionally, it was announced that progress would be monitored by Health Canada [25], [26]. These limits were established with the aim of achieving an average Canadian intake of $1 \%$ of energy as trans fat, as recommended by the WHO [23].

The Trans Fat Monitoring Program (TFMP) was established to analyze the TFA content of foods, focussing on those foods known to contribute high levels of TFAs to the Canadian diet. The primary objective of the program was to assess the food industry's performance in reducing TFAs in their products to meet the $2 \%$ and $5 \%$ limits, rather than to gather data to estimate changes in intake. Foods that were monitored over the 2-year period included pre-packaged foods, bakery products and desserts, margarines, shortenings, and foods from fast food and restaurant chains. Results were obtained from laboratory analyses conducted in three Health Canada laboratories as well as by label review and were released approximately every 6-7 months on the Health Canada website. Details and full results of the TFMP can be found in Appendices A and B.

\subsection{Changes in Food Sources of TFAs as shown by the TFMP}

Overall, results obtained from the TFMP from 2005-2009 indicate that through the voluntary approach, industry has made progress in reducing TFA levels in their products while not increasing saturated fat content [26], [28]. More than 1100 food items were analyzed over the two year monitoring period and it was found that approximately $75 \%$ of those foods analyzed and reviewed using label data were meeting the $2 \%$ and $5 \%$ limits that were recommended by the TFTF and adopted by Health Canada [28] (see Appendix B).

The results also demonstrated that, as of 2008-2009 as reported in the $4^{\text {th }}$ data set, there remain certain segments of the food supply that are not fully meeting the targets [26], [28]. For example, products that could still be found to contain high levels of TFAs (from 5\%-67\% trans fat of total fat) included hard margarines, garlic spreads, shortenings, coffee whitener, garlic bread, soft margarines, desserts, and bakery products (cookies, donuts, croissants, tarts, pies, brownies) [26], [28].

\subsection{Current Trans Fat Intakes in Canada}

The 2008 average intake of TFAs by Canadians was estimated using data obtained from the Canadian Community Health Survey (CCHS) Cycle 2.2 on Nutrition (2004), data collected from the TFMP, and by making certain assumptions regarding TFAs in the food supply. This allowed Health Canada to verify that these estimates, which were done for the TFTF based on earlier provincial data, were still valid using more current, nationally representative data. The methodology employed and the resulting estimate of trans fat intakes in Canada are described below.

\subsubsection{Methodology}

The CCHS Cycle 2.2 was a nutrition-focussed survey carried out by Statistics Canada that included data from over 33,000 respondents from all provinces, excluding the territories [31]. For this survey, a 24-hour recall was completed on all respondents, with a repeat recall done on a subset of over 10,000 respondents. This analysis included respondents aged one year and over; respondents with null or invalid recalls and breastfed children were excluded.

Trans and saturated fat composition values were obtained for a number of foods at two time points: 2004 and 2008. Trans and saturated fat composition values for 2004 were obtained from the archived records of the CNF [32] and from the NSS databases used during this time period. Trans and saturated fat composition values for 2008 were obtained from laboratory analyses of food products as part of the TFMP. The 2008 trans fat composition estimates were calculated as the average for the brands sampled for a given food, taking the average weighted by sales volume when available. 
Trans and saturated fat composition values when available were applied to foods reported in the CCHS Cycle 2.2 and all recalls were then combined to obtain the total trans and saturated fat consumed by respondents during their recall day. Usual intake distributions were estimated using the Software for Intake Distribution Estimation (SIDE) [33], and the age-sex groups were pooled for the 2008 data as they were in the 2005 modelling conducted for the TFTF [23].

Population weights were applied to obtain representative estimates. The Bootstrap replication method was used to calculate standard errors for the estimates of trans fat intake distributions [34]. Reliability rules based on the Coefficient of Variation (CV) were applied to identify estimates of marginal reliability $(16.6 \%<\mathrm{CV} \leq 33.3 \%)$ and to suppress estimates of unacceptable reliability $(\mathrm{CV}>$ $33.3 \%$ ). The Bootstrap replication method accounts only for the sampling error. There are other sources of error not quantified in this report such as respondents misunderstanding questions or answers being incorrectly processed. In particular, the methodology does not propagate to the population estimates the potential variation between the nutrient composition of brands of products consumed by respondents. As a result, care must be exercised in interpreting the standard errors and confidence intervals (CI) estimated in this report.

\subsubsection{Results}

For all Canadians aged one year and above, average trans fat intakes (from all sources) were estimated to be $3.44 \pm$ $0.03 \mathrm{~g} /$ day or $1.42 \pm 0.01 \%$ of energy [28]. Figure 2 depicts the decline in average trans fat intakes (g/day) by Canadians since 1995 and compares the intakes to the WHO recommended limit. On average, while trans fat intakes of Canadians have dropped by $1.5 \mathrm{~g} /$ day or $0.8 \%$ of energy since 2004, they are still above the WHO recommended limit of $1 \%$ of overall energy.

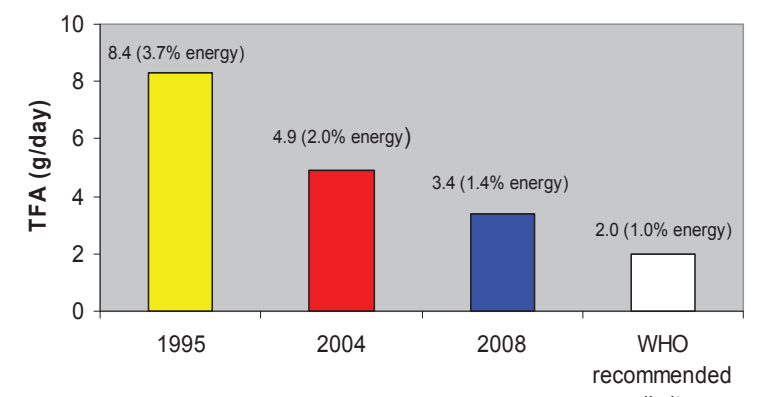

limit

Figure 2. Average trans fat intakes ( $\mathrm{g} /$ day) of Canadians 1 year and above in 1995, 2004, and 2008 vs. the World Health Organization's (WHO) recommended limit.

Average intakes of trans fat (as \% of energy) by Canadians were calculated for certain age-sex groups and are listed in Table 1 [28]. The 2008 data shows that the sub-group that appears to have the highest intake of trans fats on a \% energy basis is children; the same observation is made from the 2004 data. According to Table 1, current average trans fat intakes for children (1-8 years) are equivalent to $1.55-1.57 \%$ of overall energy. Another subgroup with high levels of trans fat intakes appears to be women 71 years and above, whose average trans fat intakes are equivalent to $1.47 \%$ of overall energy.

\begin{tabular}{|l|c|c|c|}
\hline \multicolumn{1}{|c|}{$\begin{array}{c}\text { DRI age-sex } \\
\text { group }\end{array}$} & Sample & \multicolumn{2}{c|}{ Trans \% of Energy } \\
\cline { 3 - 4 } & Size & 2004 & 2008 \\
\hline Children 1-3y & 2117 & 2.07 & 1.55 \\
\hline Children 4-8y & 3235 & 2.31 & 1.57 \\
\hline Boys 9-13y & 2080 & 2.31 & 1.54 \\
\hline Boys 14-18y & 2288 & 2.25 & 1.53 \\
\hline Girls 9-13y & 1980 & 2.32 & 1.54 \\
\hline Girls 14-18y & 2277 & 2.17 & 1.52 \\
\hline Males 19-30y & 1804 & 2.01 & 1.40 \\
\hline Males 31-50y & 2596 & 1.94 & 1.38 \\
\hline Males 51-70y & 2550 & 1.89 & 1.36 \\
\hline Males 71+y & 1520 & 1.92 & 1.44 \\
\hline Females 19-30y & 2017 & 2.05 & 1.39 \\
\hline Females 31-50y & 2755 & 1.94 & 1.39 \\
\hline Females 51-70y & 3201 & 1.87 & 1.36 \\
\hline Females 71+y & 2610 & 1.96 & 1.47 \\
\hline All Adults 19+y & 19053 & 1.94 & 1.39 \\
\hline All Person 1+y & 33030 & 2.01 & 1.42 \\
\hline
\end{tabular}

Table 1. Estimated trans fat intakes as percent of energy in 2004 vs. 2008 in different age-sex groups in Canada [28]. The results contained in this table are based on the Canadian Community Health Survey - Cycle 2.2 on Nutrition, Statistics Canada, 2004.

The usual intake distributions of trans fat (as \% of energy) were also calculated for certain age-sex groups (Table 2) [28]. The 95th percentiles for all age-sex groups have dropped from approximately $3.00 \%$ in 2004 to $2.12 \%$ in 2008. The 95th percentile for males 51 years and older is the highest at $2.30 \%$ of overall energy. The 5 th percentile for both boys and girls 9-18 years of age are reported to be $1.22 \%$ and $1.06 \%$ of energy. This indicates that almost all children and teenagers exceed the trans fat limit of $1 \%$ energy intake recommended by the WHO.

Estimations were also calculated for average saturated fat intakes. The results indicate that average saturated fat intakes have remained constant since 2004 [28]. For all Canadians aged one year and above, saturated fat intakes are estimated now to be on average, $25 \mathrm{~g} /$ day which is the same estimate from 2004 [28]. This suggests that many food manufacturers are replacing TFAs with mono- and poly-unsaturated fats and not with saturated fat. This was confirmed through the scientific assessment of the full fatty acid profile of the foods that were included for analysis in the TFMP [28]. 


\begin{tabular}{|c|c|c|c|c|c|c|c|c|c|}
\hline \multirow[b]{2}{*}{ Age-Sex } & \multirow[b]{2}{*}{ Sample Size } & \multirow[b]{2}{*}{ Year } & \multicolumn{7}{|c|}{ Percentile } \\
\hline & & & 5 th & $10^{\text {th }}$ & 25th & 50th & $75^{\text {th }}$ & 90th & 95th \\
\hline \multirow[t]{2}{*}{ Boys 9-18y } & 4368 & 2004 & 1.55 & 1.70 & 1.96 & 2.27 & 2.62 & 2.96 & 3.18 \\
\hline & & 2008 & 1.22 & 1.20 & 1.34 & 1.51 & 1.71 & 1.91 & 2.04 \\
\hline \multirow[t]{2}{*}{ Girls 9-18y } & 4257 & 2004 & 1.58 & 1.71 & 1.94 & 2.22 & 2.53 & 2.82 & 3.00 \\
\hline & & 2008 & 1.06 & 1.15 & 1.30 & 1.49 & 1.73 & 1.96 & 2.12 \\
\hline \multirow[t]{2}{*}{ Males $19-50 y$} & 4400 & 2004 & 1.16 & 1.31 & 1.58 & 1.92 & 2.29 & 2.67 & 2.91 \\
\hline & & 2008 & 0.90 & 0.99 & 1.15 & 1.36 & 1.59 & 1.81 & 1.96 \\
\hline \multirow[t]{2}{*}{ Males 51+y } & 4070 & 2004 & 0.96 & 1.11 & 1.40 & 1.80 & 2.27 & 2.78 & 3.12 \\
\hline & & 2008 & 0.71 & 0.82 & 1.03 & 1.31 & 1.66 & 2.04 & 2.30 \\
\hline \multirow[t]{2}{*}{ Females $19-50 y$} & 4772 & 2004 & 1.27 & 1.40 & 1.65 & 1.95 & 2.30 & 2.64 & 2.85 \\
\hline & & 2008 & 0.92 & 1.00 & 1.16 & 1.36 & 1.59 & 1.82 & 1.97 \\
\hline \multirow[t]{2}{*}{ Females $51+y$} & 5811 & 2004 & 1.10 & 1.24 & 4.50 & 1.84 & 2.23 & 2.63 & 2.89 \\
\hline & & 2008 & 0.79 & 0.89 & 1.08 & 1.33 & 1.64 & 1.96 & 2.18 \\
\hline
\end{tabular}

Table 2. Usual distributions of estimated trans fat intakes as percent of energy in 2004 vs. 2008 in different age-sex groups in Canada [28]. The results contained in this table are based on the Canadian Community Health Survey - Cycle 2.2 on Nutrition, Statistics Canada, 2004.

The estimates of trans fat intake were calculated using the monitoring data that was analyzed until late 2008/early 2009. More recently a Cost Benefit Analysis (CBA) was commissioned by Health Canada to estimate the potential costs and benefits of further efforts to reach the target of $1 \%$ [35]. Interviews conducted as part of the CBA indicated that some other companies were ready to roll out new products that were meeting the trans fat limits in a matter of weeks or by the end of 2009 [35]. Thus, it is possible that there were additional reductions in trans fat intakes resulting from food reformulation since the $1.42 \%$ of energy estimate was calculated. However, decreases in trans fat intake are not expected to be as large as in past years, since most companies that expressed their intent to voluntarily reduce TFA content in their foods have already done so. Therefore, the authors of the CBA decided to assume that further reductions since the last data collection would occur at half of the average rate of the previous 4 years (from $2.01 \%$ to $1.42 \%$ of energy intake over four years, or approximately $0.15 \%$ per year, and then an approximate reduction of $0.075 \%$ energy). Based on this assumption, the average trans fat intake would be estimated at $1.35 \%$ of energy (with an $80 \%$ confidence interval of $0.92 \%$ to $1.93 \%$ ) in 2009 [35], a year after the completion of the monitoring program, which is still above the WHO recommendation of $1 \%$ of energy. In children, the 2009 average trans fat intake would be estimated at $1.49 \%$.

If we were to continue with the assumption that there have been additional reductions in trans fat intakes since the $1.42 \%$ of energy estimate was calculated, and that additional reductions continued at the same rate of $0.075 \%$ energy per year, the estimated trans fat intakes in 2012 would be $1.12 \%$ of energy and $1.27 \%$ of energy in children. However, in estimating the anticipated health benefits of the reductions in trans fat intake, the CBA assumed that there would not be any further reductions in trans fat intakes in Canada beyond the 2009 levels, i.e. over 2010-2029 [35], based on interviews with food industry stakeholders about their intent to make further reductions in trans content of foods. Therefore, assumptions of similar reductions beyond 2009 as in previous years have not been substantiated. Further analysis would be required to confirm whether suitable alternative ingredients for troubled sectors have been developed and whether or not there has been uptake of alternatives in these sectors leading to further reductions.

\subsection{Additional Considerations}

\subsubsection{Availability of High TFA Foods}

Among the foods that remain high in TFA are some house brand products that are still made with $\mathrm{PHO}$ and do not meet the recommended trans fat limits [26, [28]. There are at least three examples of the same margarine manufacturer producing two lines of margarines, one that contains trans fat and one that is trans fat-free [26], [28]. The continued marketing of high TFA products such as soft margarines, shortening, hard margarines, and bakery products that have TFA content up to $21 \%, 31 \%, 40 \%$, and $45 \%$ of total fat, respectively, is of particular concern since these categories of foods have been and continue to be top contributors to trans fat intake by Canadians [16], [17], [26], [28].

\subsubsection{Food Service Establishments}

The beneficial impact of Canadian nutrition labelling regulations on alerting consumers to the levels of trans fat does not extend to foods sold in restaurants and food service establishments as the nutrition labelling regulations only apply to prepackaged foods. Recently it was reported that most Canadians eat out (48\%-74\%) or order take-out (20-67\%) about once per week [36] and on 
a given day, one out of four adults and children in Canada eats or drinks a food or beverage in a fast food outlet [37]. This figure is likely higher since the report also indicated that an additional $23 \%$ consumed food in some other combination (either something prepared at a restaurant, bar, school and non-school cafeteria, etc.) [37]. Furthermore, information from nutrition surveys indicates that $22 \%$ of the average trans fat intake of Canadian adults (and as much as $31 \%$ in the case of males aged 19 to 30 years) is provided by foods consumed away from home, often in fast food restaurants and other food service environments [23]. Results from the TFMP suggest that while a number of popular fast-food and family restaurant chains in Canada have been successful in decreasing TFA levels, there are still establishments that continue to offer menu items high in TFAs [26], [28].

\subsubsection{Analysis of specific sub-populations and socioeconomic considerations}

Besides overall estimates of exposure in the population, the potential for some groups to have higher exposure to trans fat needs to be considered. As noted in the exposure assessment section, exposure in children tends to be higher than exposure in adults on the basis of percent energy.

Another potentially vulnerable population includes people living in remote areas such as the Canadian Inuit population. Over the last five decades or so, Inuit populations have transitioned from a traditional, marine diet to one which incorporates more processed foods, typical of a western diet. Foods containing industrially produced TFAs offer qualities that are required for processed foods in remote communities, namely, storability at room temperature and a longer shelf-life. A recent dietary survey conducted in 2004-2005 in Inuit populations from Nunavik, Canada and Greenland indicated that on average, store-bought foods accounted for $75 \%$ and $84 \%$ of energy intakes, respectively [38]. This study showed that while the contribution of energy from store-bought foods was comparable between the two Inuit populations, the average trans fat intakes among the Nunavik Inuit were three times higher than those of the Greenland Inuit (as measured by the fatty acid composition of erythrocyte membrane phospholipids) [38]. Furthermore, while Inuit youth consumed a significantly higher proportion of storebought foods than their elders $(90 \%$ of calories vs. $70 \%$ of calories) in both populations, erythrocyte TFA levels were similar across all age groups in Greenland Inuit, while in Nunavik youth had significantly higher erythrocyte TFA levels than their elders $(0.67 \%$ vs. $0.39 \%$ ). The study reported that the availability of good quality store-bought foods, at least as it relates to trans fat, was better for the Greenland Inuit because most industrially produced foods sold in Greenland are imported from Denmark, where a trans limit of $2 \%$ of total fat has been imposed since 2003 [38].

While familiarity with the food product is a factor influencing Canadians' food buying practices [39], one of the top factors influencing food buying decisions is cost [36], [39]. Research shows a negative relationship between price and the SFA and TFA contents of margarines [40]. It was reported that margarines sold on the Canadian market that are lower in SFA, TFA, and the sum of SFA+TFA, cost significantly more than margarine with higher levels of these fats [40]. Additionally, despite controlling for confounding variables such as package size, store type, and brand, this relationship was still seen [40]. More recent data is consistent with this price disparity among high and low TFA margarines [41]. In 2002, those that were "trans-fat free" (i.e. less than $0.2 \mathrm{~g}$ of trans fat per reference amount and serving of stated size and low in saturated fats) cost $\$ 4.62$ per $\mathrm{kg}$ and those that were not "trans-fat free" cost $\$ 3.05$ per $\mathrm{kg}$. In comparison, in 2006 those that were "trans-fat free" cost $\$ 5.10$ per $\mathrm{kg}$ and those that were not "trans-fat free" cost \$3.55 per kg [41]. Similar research indicates that nutritionally improved products tend to be higher in price [42] which is of a particular concern for lower income groups. Budget constraints have a significant influence on lower income groups making them very price sensitive. The implication is that these groups will be likely to have a higher exposure to trans fat through their selection of lower priced foods [43].

\section{Risk Characterization}

Coronary heart disease is among the leading causes of death in Canada contributing to approximately 50,000 annual deaths [44]. The heart health effects of TFAs are well known: they raise LDL-cholesterol and lower HDLcholesterol, which leads to increased risk of CHD. Even very low intakes of TFAs may increase the risk of CHD [5].

In prospective cohort studies reviewed by Mozaffarian and Clarke, each $2 \%$ energy replacement of trans fat with monounsaturated or polyunsaturated fat lowered the CHD risk by $21 \%$ or $24 \%$, respectively [7]. Based on these rates (and using the more conservative estimate of trans fat intake based on the interviews summarized in the 2009 CBA [35]), reducing the average trans fat intakes of children from $1.49 \%$ to $1 \%$ of overall energy would decrease the $\mathrm{CHD}$ risk by $5-6 \%$. Reducing the average trans fat intakes of adults from $1.35 \%$ (using the more conservative trans fat intake estimate) to $1 \%$ of overall energy would decrease the CHD risk by $3-4 \%$.

Population-attributable risks based on epidemiological data, such as those mentioned above, may overestimate 
the true effect of eliminating a risk factor owing to other unrelated (competing) risk factors [45], [46]. Therefore further estimates of decreased risk were obtained from controlled trials and short term clinical studies. On the basis of predicted changes in the total-cholesterol:HDL-C ratio from controlled trials, according to Mozaffarian and colleagues, $3 \%$ of CHD events could be averted when trans fat intakes are reduced from $2.1 \%$ energy to $1.1 \%$ energy [1]. As cited by the Food and Drug Administration, findings from other short-term feeding trials that measured changes in serum lipids (LDL+HDL), showed a $0.184 \%, 0.287 \%$ and $0.296 \%$ reduced risk of CHD for each $0.1 \%$ of energy replacement of TFAs with SFAs, MUFAs or PUFAs, respectively [47]. This equals an average $2.6 \%$ reduction in the risk of $\mathrm{CHD}$ for every $1 \%$ energy replacement of TFAs with SFAs, MUFAs and PUFAs $\left[((0.184 \%+0.287 \%+0.296 \%) / 3)^{*} 10=2.6 \%\right]$.

To account for the range of published estimates using clinical trials measuring changes in serum lipids, an average of the two estimates, $2.6 \%$ and $3.0 \%$, is taken. Thus, there is an estimated reduction in CHD risk of $2.8 \%$ for each $1 \%$ of energy replacement of TFAs with SFAs, MUFAs or PUFAs (in equal proportions).

Using the average estimate of $2.8 \%$, on the basis of the changes in cholesterol levels alone, decreasing the average trans fat intakes of children from $1.49 \%$ to $1 \%$ of overall energy would decrease the CHD risk by $1.37 \%$. Reducing the average trans fat intakes across all ages from $1.35 \%$ to $1 \%$ of overall energy would decrease the lifetime CHD risk by $0.98 \%$. According to the CBA commissioned by Health Canada that factored in the reduced risk of $\mathrm{CHD}$ along with annual growth rate of heart attack cases in Canada, this further reduction of average trans fat intake to $1 \%$ of energy is conservatively estimated to prevent an average of 12,354 heart attack cases in Canada over 2010-2029 [35].

\section{Conclusion}

Collectively, the monitoring program results indicate that, while there are a large number of foods on the market in most categories meeting the $2 \%$ and $5 \%$ trans fat limits recommended by the TFTF, there were still some foods that contain high levels of TFA [26], [28].

The progress made by the industry to reformulate and decrease the TFA content of their products has been reflected in an overall decrease in the trans fat intakes of Canadians. However, the estimated average trans fat intake for Canadians in 2008 at $1.42 \%$ of energy continues to be above the WHO recommendation that average trans fat intake be limited to less than $1 \%$ of total energy. It also confirms that the average trans fat intakes of Canadians could reach $1 \%$ of total energy if most products were reformulated to meet the $2 \%$ and $5 \%$ limit.
Despite the progress made by industry to reduce the trans fat content of their foods, there remain foods in the Canadian market place that contain high levels of trans fat. Further reductions in trans fat levels in the Canadian food supply are needed to meet the target of $1 \%$ of energy, the associated public health objectives, and the protection of vulnerable populations.

\section{Acknowledgements}

The authors would like to thank: William Yan, Maya Villeneuve, Claude Gagnon, Isabelle Rondeau, Brian Lampi, Zeshawn Awan, Amanda Whitfield, Michael Masotti, Valerie Casey, Dayani Mohottalage, William Lillycrop, Mary Meleta, Lynn Wong, Tran Ng, Yu Gao, Keri Kwong, Shirley Chalouh, Peter Pantazopoulos, Hasantha Gunaratna, Richard Blagden, Veronica Roscoe, Tom Krakalovich, Gary Neumann, and Gary Lombaert for their extensive and invaluable contributions to the various aspects of this paper. The authors would also like to thank Lydia Dumais, Kevin Cockell, and Lisa Pavone for their helpful reviews.

\section{APPENDIX A - Trans Fat Monitoring Program}

On June 20, 2007, Health Canada adopted the recommendations of the TFTF with respect to the amount of TFA in foods and announced the Trans Fat Monitoring Program [25]. The Minister of Health called on the food industry to achieve the $2 \%$ and $5 \%$ limits within two years [25].

Health Canada has been analyzing TFAs in foods intermittently since the 1970's, focusing then on margarines [13]. The analysis of TFAs in foods increased at the time the TFTF was established in order to support their work. The Trans Fat Monitoring Program was established following the announcement of the Minister in June 2007 to analyze the TFA content of foods that were, as indicated by earlier surveys, significant sources of TFAs, i.e. foods with high levels of TFAs or foods with lower levels of TFAs that were consumed in large quantities by a large number of consumers.

For prepackaged foods, the individual products that were chosen for laboratory analysis were representative of the majority of products sold within a particular food category. In most cases, they represented a group of products that covered approximately $80 \%$ of the market share (as volume share). Market share data was purchased from AC Nielsen [27]. Bakery products that were predominantly unlabelled items from various grocery stores were also chosen for laboratory analysis since they represent foods that were previously identified as significant sources of TFAs [16], [17], [23]. Items were collected from major grocery stores that represented retail chains found across Canada. 
Foods from the major fast food chains, family restaurants, donut/coffee shops, and restaurants serving various ethnic cuisines underwent laboratory analysis as well. A smaller sample of foods were also collected and analysed from small and medium-sized family and quick service restaurants, as well as cafeterias located in institutions. All laboratory analyses were conducted from 2005-2009.

For the label review, the food categories chosen were those that were previously identified as significant sources of TFAs [16], [17], [23]. The individual products within each of these categories were selected based on market share data. Collectively, groups of products represented more than $99 \%$ of the market share (as volume share). However, certain products were not collected because previous monitoring data suggested that the levels of TFAs were already low in these products and so a label review of these products was not repeated. All food labels were collected for label review in March and October 2008 from major grocery stores from across Canada (Toronto, ON; Scarborough, ON; Vancouver, BC; Halifax, NS; and Montreal, QC).

Three Health Canada laboratories (Ottawa, Toronto, and Winnipeg) performed the collection and laboratory analyses as well as the label review. The full details of the sample collection, analytical methods, quality assurance program, were posted on the Health Canada website along with the data [26], [28].

Briefly, the food samples were analysed by the Association of Official Analytical Chemists (AOAC) Method 996.06 [29], the recommended method for TFA analysis in Canada. This laboratory procedure and methodology is used to determine the total fat and fatty acids in a wide variety of foods that require nutrition labelling in Canada and the United States.

\begin{tabular}{|c|c|c|c|c|c|c|c|}
\hline Item & $\begin{array}{l}\text { Total } \\
\text { samples }\end{array}$ & $\begin{array}{l}\text { Number } \\
\text { of samples } \\
\text { meeting }\end{array}$ & $\begin{array}{l}\text { Number of } \\
\text { samples not } \\
\text { meeting }\end{array}$ & $\begin{array}{l}\text { Percent of } \\
\text { samples } \\
\text { meeting }\end{array}$ & $\begin{array}{lr}\text { Percent of } \\
\text { samples not } \\
\text { meeting }\end{array}$ & $\begin{array}{l}\text { Min. \% } \\
\text { TFA }^{*}\end{array}$ & $\begin{array}{l}\text { Max \% } \\
\text { TFA }\end{array}$ \\
\hline cookies & 79 & 53 & 26 & 67 & 33 & 0.0 & 33.3 \\
\hline crackers & 62 & 58 & 4 & 94 & 6 & 0.0 & 33.3 \\
\hline popcorn & 22 & 18 & 4 & 82 & 18 & 0.0 & 50.0 \\
\hline pizza & 6 & 4 & 2 & 67 & 33 & 2.2 & 9.8 \\
\hline coffee whitener & 17 & 8 & 9 & 47 & 53 & 0.0 & 66.7 \\
\hline garlic spreads & 6 & 2 & 4 & 33 & 67 & 0.6 & 17.2 \\
\hline garlic bread & 11 & 6 & 5 & 55 & 45 & 0.9 & 25.1 \\
\hline bread & 21 & 21 & 0 & 100 & 0 & 0.4 & 3.3 \\
\hline muffins & 2 & 2 & 0 & 100 & 0 & 0.5 & 1.9 \\
\hline snacks & 90 & 84 & 6 & 93 & 7 & 0.0 & 28.6 \\
\hline chicken products & 6 & 5 & 1 & 83 & 17 & 2.0 & 19.0 \\
\hline hard margarines & 6 & 0 & 6 & 0 & 100 & 35.7 & 44.5 \\
\hline soft margarines & 37 & 23 & 14 & 62 & 38 & 0.5 & 32.8 \\
\hline shortening & 4 & 2 & 2 & 50 & 50 & 3.8 & 30.9 \\
\hline lard & 4 & 4 & 0 & 100 & 0 & 1.1 & 2.0 \\
\hline $\begin{array}{l}\text { baked packaged } \\
\text { desserts }\end{array}$ & 87 & 73 & 14 & 84 & 16 & 0.0 & 28.6 \\
\hline granola bars & 21 & 17 & 4 & 81 & 19 & 0.3 & 17.5 \\
\hline instant noodles & 22 & 22 & 0 & 100 & 0 & 0.0 & 0.9 \\
\hline frozen potatoes & 21 & 20 & 1 & 95 & 5 & 0.0 & 37.5 \\
\hline $\begin{array}{l}\text { frozen packaged } \\
\text { desserts }\end{array}$ & 49 & 36 & 13 & 73 & 27 & 0.0 & 22.2 \\
\hline snack pudding & 27 & 21 & 6 & 78 & 22 & 0.0 & 33.3 \\
\hline appetizers & 109 & 93 & 16 & 85 & 15 & 0.0 & 40.9 \\
\hline entrées/dinners & 85 & 69 & 16 & 81 & 19 & 0.0 & 12.5 \\
\hline
\end{tabular}

Table 3. Results of prepackaged foods collected and analysed (label review and laboratory analysis) from 2005-2008.

* For samples that were laboratory analyzed, the $0.0 \%$ indicates that the level of trans fat detected was below the limit of detection. For samples that underwent label review, the $0.0 \%$ indicates the amount of trans fat that is declared on the label and thus subject to labelling regulations (including rounding). 


\begin{tabular}{|l|l|l|l|}
\hline Item & Total number of samples & $\begin{array}{l}\text { Percent of samples not } \\
\text { meeting TFA limit }\end{array}$ & $\begin{array}{l}\text { range of TFA in samples } \\
\text { (as \% of total fat) }\end{array}$ \\
\hline hard margarines & 6 & 100 & $35.7-44.5$ \\
\hline garlic spreads & 6 & 67 & $5.1-17.2$ \\
\hline shortening & 4 & 50 & $30.6-30.9$ \\
\hline coffee whitener & 17 & 53 & $13.3-66.7$ \\
\hline garlic bread & 11 & 45 & $11.5-25.1$ \\
\hline soft margarines & 37 & 38 & $14.7-32.8$ \\
\hline pizza & 6 & 33 & $7.3-9.8$ \\
\hline cookies & 79 & 33 & $6.7-33.3$ \\
\hline
\end{tabular}

Table 4. Prepackaged food with high levels of TFAs.

The data were presented alphabetically by food category in a standard format and included the sampling date, the percentage of total fat in the food, as well as TFA and SFA content as a percentage of total fat. All results were posted on the Health Canada website. Results from the $1^{\text {st }}, 2^{\text {nd }}, 3^{\text {rd }}$, and $4^{\text {th }}$ set of trans fat monitoring data were released in December 2007, July 2008, February 2009, and September 2009 respectively [26] and published in 2009 [28]. The results presented in this risk assessment include data from all four data sets.

\section{APPENDIX B - Trans Fat Monitoring Program Results}

\section{Prepackaged Foods}

In total, 792 prepackaged foods (not including the repeated items) were collected and analysed (by label review and laboratory analysis) from 2005-2008. The food categories included are listed in Table 3. Based on the most recent results, approximately $76 \%$ (or 655 out of the 792) of prepackaged foods analyzed are meeting the $2 \%$ and $5 \%$ trans fat limits. The food categories with the highest percentages of items now meeting the limits include: instant noodles (100\%), lard (100\%), muffins $(100 \%)$, breads and buns $(100 \%)$, frozen potatoes $(95 \%)$, crackers $(94 \%)$, snacks $(93 \%)$, baked packaged desserts $(84 \%)$, popcorn $(81 \%)$, and granola bars $(80 \%)$. The food categories with the lowest percentages of items now meeting the trans fat limits include: hard margarines $(0 \%)$, garlic spreads $(33 \%)$, shortenings $(50 \%)$, coffee whitener $(47 \%)$, garlic bread $(55 \%)$, soft margarines $(62 \%)$, pizza $(67 \%)$, and cookies $(67 \%)$.

The TFA content of some foods is still quite high, with levels as high as nearly $70 \%$. For example, the TFA content of some coffee whiteners ranges from $13.3 \%$ $66.7 \%$, the TFA content of some popcorn products ranges from $20.0 \%-50.0 \%$, and the TFA content of some soft margarines ranges from $14.7 \%-32.8 \%$. Other high TFA-containing foods are listed in Table 4.
Market share for most of the foods that are still high in TFAs is marginal except for the cookies that are not meeting the trans fat limits, which collectively represent close to $10 \%$ of the market (as volume share). Also, the high TFA-containing soft margarines represent approximately $16 \%$ of the market and the high TFAcontaining hard margarines represent close to $30 \%$ of the market. The proportion of the market that these foods actually represent is likely higher since the market share of house brands, which is unknown for individual products, has not been included. There are a number of house brand products that are still using $\mathrm{PHO}$ and as such are not meeting the trans fat limits.

In all other cases, the food products that are higher than the trans fat limits represent less than $5 \%$ of the market. For example the snack products collectively represent less than $1 \%$ of the market, the popcorn products collectively represent less than $3 \%$ of the market, and the garlic spreads collectively represent less than $0.5 \%$ of the market.

\section{Bakery products from grocery stores:}

The trans fat monitoring program analysed 81 bakery products from various grocery stores. The results from the bakery products analyses indicate that the following were meeting the $5 \%$ TFA limit: $25 \%$ of croissants $(n=16), 45 \%$ of danishes $(n=11), 36 \%$ of pies $(n=11), 67 \%$ of tarts $(n=$ $15), 43 \%$ of cakes $(\mathrm{n}=14), 45 \%$ of brownies $(\mathrm{n}=11)$, and $33 \%$ of donuts $(n=3)$. The details can be found in Table 5 .

On average, out of the total of 81 bakery products, 46 (or $58 \%$ ) were meeting the trans fat limit of $5 \%$ of total fat. The TFA content of those 46 items that were still high in TFAs ranged from $5.4 \%$ TFA (tart) to $39.2 \%$ (danish) and $43.7 \%$ TFA (croissant). Thus, the levels of certain bakery products remain quite high. There are however examples of low trans fat bakery products in each category, some with levels as low as $0.6 \%$ TFA, indicating that it is possible to reformulate and produce low trans fat products of all types, including croissants and tarts. 


\begin{tabular}{|l|l|l|l|l|l|}
\hline Item & $\begin{array}{l}\text { Total } \\
\text { samples }\end{array}$ & $\begin{array}{l}\text { Number of } \\
\text { samples meeting }\end{array}$ & $\begin{array}{l}\text { Number of samples } \\
\text { not meeting }\end{array}$ & $\begin{array}{l}\text { Percent of } \\
\text { samples meeting }\end{array}$ & $\begin{array}{l}\text { Percent of samples } \\
\text { not meeting }\end{array}$ \\
\hline croissants & 16 & 4 & 12 & 25 & 75 \\
\hline danishes & 11 & 5 & 6 & 45 & 55 \\
\hline pies & 11 & 4 & 7 & 36 & 64 \\
\hline tarts & 15 & 10 & 5 & 67 & 33 \\
\hline cakes & 14 & 6 & 8 & 43 & 57 \\
\hline brownies & 11 & 5 & 6 & 45 & 55 \\
\hline donuts & 3 & 1 & 2 & 33 & 67 \\
\hline
\end{tabular}

Table 5. Results of bakery items collected from grocery stores.

\begin{tabular}{|l|l|l|l|l|}
\hline Item & $\begin{array}{l}\text { Fat } \\
(\% \text { by weight of food })\end{array}$ & $\begin{array}{l}\text { TFA } \\
(\% \text { of total fat })\end{array}$ & $\begin{array}{l}\text { SFA } \\
\text { (\% of total fat })\end{array}$ & $\begin{array}{l}\text { TFA + SFA } \\
\text { (\% of total fat })\end{array}$ \\
\hline croissants & 20.6 & 0.7 & 45.1 & 45.8 \\
\hline croissants & 20.5 & 43.7 & 18.9 & 62.6 \\
\hline danishes & 13.1 & 1.0 & 44.6 & 45.6 \\
\hline danishes & 9.3 & 39.2 & 22.9 & 62.1 \\
\hline blueberry pie & 14.4 & 0.8 & 46.3 & 47.1 \\
\hline lemon meringue pie & 8.6 & 29.0 & 22.5 & 51.5 \\
\hline butter tart & 18.9 & 0.6 & 41.0 & 41.6 \\
\hline fruit tarts & 10.0 & 23.0 & 39.4 & 62.4 \\
\hline $\begin{array}{l}\text { chocolate cake } \\
\text { with icing }\end{array}$ & 25.6 & 0.8 & 46.2 & 47.0 \\
\hline chocolate cake & 13.7 & 27.1 & 32.2 & 59.3 \\
\hline brownies & 14.8 & 0.7 & 32.6 & 33.3 \\
\hline brownies & 9.9 & 26.2 & 21.9 & 48.1 \\
\hline donut & 17.7 & 3.4 & 45.1 & 48.5 \\
\hline donut & 27.8 & 26.0 & 33.5 & 59.5 \\
\hline
\end{tabular}

Table 6. Data indicating the sum of trans fat + saturated fat decreasing in low trans fat bakery products.

Bakery products are known to require a hard fat to maintain functional characteristics. One such substitute for trans fat is saturated fat. The data, as reported in Table 6 , indicates that while saturated fat in some of the low trans fat bakery products have increased, in each case the sum of trans fat + saturated fat is much lower than the high trans fat bakery products. This suggests that a much lower amount of saturated fat is required to produce a comparable product. There are also examples of low trans fat bakery products with low saturated fat levels as well, indicating the replacement of TFAs with other fats such as monounsaturated and polyunsaturated fats.

The results also indicate that the majority of the products that are high in trans fat, and thus not meeting the limit, do not have a Nutrition Facts table. These include in-store bakery products that are exempt from nutrition labelling requirements. Specifically, 62 products were not labelled with Nutrition Facts tables versus 19 products that were labelled with Nutrition Facts tables. As indicated in Table 7 , of the 62 products not labelled, 38 of $(61 \%)$ were high in trans fat. Whereas out of the 19 products that were labelled eight (42\%) were high in trans fat.
Foods from restaurants serving various ethnic cuisines:

Rates of meeting the trans fat limit were high for many menu items from restaurants serving various ethnic cuisines, including Thai, Vietnamese, Caribbean, Chinese, Japanese, and East Indian. In total, 70 menu items were collected from 16 different establishments and 63 (or 90\%) of those items were meeting the TFA limit. Foods collected and analysed included fried foods and those that are pastry-based such as: naan bread, samosa, Chinese cookies, mooncake, General Tao's chicken, fried beef and pork, roti, egg rolls, and spring rolls.

Foods from fast food chains, family restaurants, and coffee shops:

Foods collected and analyzed from 2006-2008 included: french fries, chicken products (such as chicken nuggets and chicken strips), fish products, onion rings, donuts, cookies (including biscuits and croissants), miscellaneous (cheese sticks, hash browns), desserts, muffins, pizzas, and pizza dipping sauces. 


\begin{tabular}{|l|l|l|l|l|l|}
\hline Item & $\begin{array}{l}\text { Total } \\
\text { samples }\end{array}$ & $\begin{array}{l}\text { Number of } \\
\text { samples meeting }\end{array}$ & $\begin{array}{l}\text { Number of samples } \\
\text { not meeting }\end{array}$ & $\begin{array}{l}\text { Percent of } \\
\text { samples meeting }\end{array}$ & $\begin{array}{l}\text { Percent of samples } \\
\text { not meeting }\end{array}$ \\
\hline labelled & 19 & 11 & 8 & 58 & 42 \\
\hline unlabelled & 62 & 24 & 38 & 39 & 61 \\
\hline
\end{tabular}

Table 7. Bakery items labelled and unlabelled that are high and low in trans fat.

\begin{tabular}{|c|c|c|c|c|c|}
\hline Item & $\begin{array}{l}\text { Total } \\
\text { samples }\end{array}$ & $\begin{array}{l}\text { Number of } \\
\text { samples meeting }\end{array}$ & $\begin{array}{l}\text { Number of samples } \\
\text { not meeting }\end{array}$ & $\begin{array}{l}\text { Percent of } \\
\text { samples meeting }\end{array}$ & $\begin{array}{l}\text { Percent of samples } \\
\text { not meeting }\end{array}$ \\
\hline pizza & 13 & 13 & 0 & 100 & 0 \\
\hline pizza dipping sauce & 8 & 8 & 0 & 100 & 0 \\
\hline muffins & 18 & 17 & 1 & 94 & 6 \\
\hline ethnic foods & 70 & 63 & 7 & 90 & 10 \\
\hline popcorn & 17 & 15 & 2 & 88 & 12 \\
\hline miscellaneous & 11 & 9 & 2 & 82 & 18 \\
\hline french fries & 90 & 71 & 19 & 79 & 21 \\
\hline chicken products & 95 & 75 & 20 & 79 & 21 \\
\hline fish products & 25 & 19 & 6 & 76 & 24 \\
\hline onion rings & 12 & 9 & 3 & 75 & 25 \\
\hline desserts & 35 & 23 & 12 & 66 & 34 \\
\hline cookies & 13 & 6 & 7 & 46 & 54 \\
\hline donuts & 35 & 10 & 25 & 29 & 71 \\
\hline
\end{tabular}

Table 8. Results of foods collected from fast food chains and family restaurants.

In total, 355 fast foods items (not including repeated items) were collected and analysed from 2006-2009. Based on the most recent results included in Table 8 , on average $75 \%$ or 260 out of the 355 fast food items meet the $5 \%$ trans fat limits. The fast food product categories with the highest percentages that meet the limits include: pizzas (100\%), pizza dipping sauces $(100 \%)$, muffins $(94 \%)$, miscellaneous fast foods $(82 \%)$, french fries $(79 \%)$, and chicken products (79\%). Some of the fast food product categories with the lowest percentages that meet the limits are donuts (29\%), cookies $(46 \%)$, and desserts $(66 \%)$. The trans fat content in some of these foods is still quite high. For example, croissants and donuts collected from donut shops were reported to be as high as $44 \%$ trans fat and $56 \%$ trans fat, respectively, and a fried fish product from a popular family restaurant was reported to be as high as $42 \%$ trans fat.

Results from the monitoring program indicate that many of the top fast food and top family restaurant chains in Canada have been successful in reducing trans fat from menu items that have been previously high in trans fat. Revenues for these establishments, according to the 2007 Foodservice and Hospitality top 100 report [30], range from $\$ 25.5$ million to $\$ 4.2$ billion. Revenues for establishments that are still offering menu items that are high in trans fat range from $\$ 47$ million to $\$ 474.6$ million [30].

Foods from cafeteria in institutions (high schools, hospitals, college campuses, and nursing homes):

One hundred and four items from cafeterias in institutions such as high schools, hospitals, college campuses, and nursing homes were collected and analysed. While this was a small sample, it helped provide a baseline of the levels of TFAs in these types of establishments since many of these foods are not considered to be prepackaged and are exempt from the nutrition labelling regulations. Foods were collected from institutions in the following cities across Canada: Victoria, British Columbia; Winnipeg, Manitoba; Ottawa, Ontario; Montreal, Quebec; and Charlottetown, Prince Edward Island.

Foods that were collected included french fries, chicken products (such as chicken nuggets and chicken strips), fish products, onion rings, cookies, margarines, desserts, and muffins.

On average $67 \%$ or 88 out of the 104 items meet the $2 \%$ and $5 \%$ trans fat limits. The food categories with the highest percentages now meeting the limits include: muffins $(100 \%)$, chicken products $(80 \%)$, and cookies (76\%). Foods categories that had low percentages of items but are now meeting the limits were margarines (25\%), fish products $(50 \%)$, and desserts $(63 \%)$. These details are reported in Table 9. The TFA content in some of these foods is still quite high. Specifically, the TFA content of the 24 items that were still high in trans fat ranged from $5.3 \%$ (onion rings served in hospital cafeteria) to $29 \%$ (scones served in high school) to $47.0 \%$ (chicken fingers served in nursing home). 


\begin{tabular}{|c|c|c|c|c|c|}
\hline Item & $\begin{array}{l}\text { Total } \\
\text { samples }\end{array}$ & $\begin{array}{l}\text { Number of } \\
\text { samples meeting }\end{array}$ & $\begin{array}{l}\text { Number of samples } \\
\text { not meeting }\end{array}$ & $\begin{array}{l}\text { Percent of } \\
\text { samples meeting }\end{array}$ & $\begin{array}{l}\text { Percent of samples } \\
\text { not meeting }\end{array}$ \\
\hline french fries & 21 & 15 & 6 & 71 & 29 \\
\hline chicken products & 15 & 12 & 3 & 80 & 20 \\
\hline cookies & 29 & 22 & 7 & 76 & 24 \\
\hline muffins & 22 & 22 & 0 & 100 & 0 \\
\hline onion rings & 3 & 2 & 1 & 67 & 33 \\
\hline fish & 2 & 1 & 1 & 50 & 50 \\
\hline margarines & 4 & 2 & 2 & 50 & 50 \\
\hline desserts & 8 & 5 & 3 & 63 & 37 \\
\hline
\end{tabular}

Table 9. Results of foods collected from institutions (cafeteria in hospitals, on college campuses, in high schools).

The results show that foods served in cafeteria in institutions are not meeting the limits as well as foods served in other food service establishments such as restaurants and fast food chains. Two of the top food service providers/caterers are serving foods that are still high in trans fat, namely margarines (24\% TFA and $26 \%$ TFA), cookies (20\% TFA), and french fries (13\% TFA) in nursing homes and on college campuses. The revenue for two of the top food service providers/caterers ranges from 485 million to $\$ 707$ million [30].

\section{References}

[1] Mozaffarian D, Katan MB, Ascherio A, Stampfer MJ, Willett WC. 2006. Trans Fatty acids and cardiovascular disease. N Engl J Med 354:1601-1613.

[2] Nishida C, Uauy R. 2009. WHO Scientific Update on health consequences of trans fatty acids. Eur J Clin Nutr 63: S1-S4.

[3] Greyt W De, Kint A, Kellens M, Huyghebaert A. 1998. Determination of Low trans Levels in Refined Oils by Fourier Transform Infrared Spectroscopy. JAOCS 75(2):115-118

[4] Mendis S, Cruz-Hernandez C, Ratnayake WMN. 2008. Fatty acid profile of Canadian dairy products with special attention to the trans-octadecenoic acid and conjugated linoleic acid isomers. J AOAC Int. 91:811-819.

[5] Institute of Medicine. 2002. Dietary Reference Intakes for Energy, Carbohydrate, Fiber, Fat, Fatty Acids, Cholesterol, Protein, and Amino Acids. National Academies Press: Washington, D.C.

[6] Mozaffarian D, Aro A, Willet WC. 2009. Health effect of trans-fatty acids: experimental and observational evidence. Eur J Clin Nutr 63:S5-S21.

[7] Mozaffarian D, Clarke R. 2009. Quantitative effects on cardiovascular risk factors and coronary heart disease risk of replacing partially hydrogenated vegetable oils with other fats and oils. Eur J Clin Nutr 63: S22-S33.

[8] Health Canada. 2006. Dietary Reference Intake Tables. Available at: http://www.hc-sc.gc.ca/fn-an/nutrition/ reference/table/index-eng.php\#rvm Accessed: July 13, 2009
[9] World Health Organization. 2003. Diet, Nutrition and the Prevention of Chronic Diseases. WHO Technical Series Report 916: Geneva. Available at: http://www.who.int/dietphysicalactivity/publications/ trs916/en/gsfao_overall.pdf Accessed: August 25, 2009

[10] Willett WC, Stampfer MJ, Manson JE, Colditz GA, Speizer FE, Rosner BA Sampson LA, Hennekens CH. 1993. Intake of trans-fatty acids and risk of coronary heart disease among women. Lancet 341: 581-585.

[11] Ascherio A, Katan MB, Zock PL, Stampfer MJ, Willett WC. 1999. Trans fatty acids and coronary heart disease. N Engl J Med. 340(25):1994-1998.

[12] Food and Agriculture Organization of the United Nations. 2008. Fats and fatty acids in human nutrition, report of an expert Consultation, FAO. Available at: http://foris.fao.org/preview/25553-0ece4cb94ac52f9a 25af77ca5cfba7a8c.pdf. Accessed: January 6, 2012.

[13] Davignon J, Holub B, Little JA, McDonald BE, Spence M. 1980. Report of the Ad Hoc Committee on the composition of special margarines. Ministry of Supply and Services Canada, Ottawa.

[14] Health and Welfare Canada. 1990. Nutrition Recommendations: Report of the Scientific Review Committee, Ministry of Supply and Services Canada, Ottawa.

[15] Ratnayake WMN, Chen ZY. 1995. Trans-fatty acids in Canadian breast milk and diet. in Development and processing of vegetable oils for human nutrition, ed. R Przybylski and BE McDonald, pp 20-35. AOCS Press: Champaign.

[16] Innis SM, Green TJ, Halsey TK. 1999. Variability in the trans fatty acid content of foods within a food category: implications for estimation of dietary trans fatty acid intakes. J Am Coll Nutr. 18:255-260.

[17] Ratnayake, WMN, Hollywood R, O'Grady E, Pelletier G. 1993. Fatty acids in some common food items in Canada. J. Am. Coll. Nutr. 12: 651-660.

[18] Government of Canada. 2003. Regulations Amending the Food and Drug Regulations (Nutrition Labelling, Nutrient Content Claims and Health Claims). Canada Gazette 137, Part II, January 1, 2003. Available at: http://canadagazette.gc.ca/archives/p2/2003/2003-0101/html/sor-dors11-eng.html. Accessed, April 12, 2011. 
[19] CTV News. 2003. “Voortman removing trans fat from its cookies." Available at:

http://www.ctv.ca/servlet/ArticleNews/story/CTVNe ws/1069789271153_26// Accessed, July 31, 2009.

[20] USA Today. 2004. "Latest consumer hook: Trans-fatfree snacks." Available at:

http://www.usatoday.com/news/health/2004-03-31trans-fatty-usat_x.htm. Accessed, July 31, 2009.

[21] CTV News. 2004. "Frito Lay plans to cut trans fat in some snacks." Available at:

http://www.ctv.ca/servlet/ArticleNews/print/CTVNe ws/20040223/fritolay_transfatfree_20040222/20040223/

?hub=Health\&subhub=PrintStory. Accessed, July 31, 2009.

[22] Canada Parliament House of Commons. 2004. Journals of the House of Commons. 38th Parliament, 1st session, No. 30, November 23, 2004. Available at: http://www2.parl.gc.ca/HousePublications/Publicatio n.aspx?pub=journals\&mee=30\&parl=38\&ses=1\&lang uage=E. Accessed, July 13, 2009.

[23] Trans Fat Task Force. 2006. "TRANSforming the Food Supply". Ottawa, Canada. Available at: http://www.hc-sc.gc.ca/fn-an/nutrition/gras-transfats/tf-ge/tf-gt_rep-rap-eng.php. Accessed: July 13, 2009

[24] Zehaluk C, L'Abbé M. 2007. Implementation by the Food Directorate, Health Products and Food Branch, Health Canada of the recommendations for diet in the WHO Global Strategy on Diet, Physical Activity and Health. Background paper prepared for the WHO Trade and Healthy Diets Meeting, November 12-13, 2007, Executive Institute, Desautels Faculty of Management, McGill University, Montreal, Canada.

[25] Health Canada. 2007. Canada's New Government Calls on Industry to Adopt Limits for Trans Fat. Available at: http://www.collectionscanada.gc.ca/webarchives/200 71121021122/http://www.hc-sc.gc.ca/ahc-asc/media/ nr-cp/2007/2007_74_e.html. Accessed, April 12, 2011.

[26] Health Canada. 2007. Trans Fat Monitoring Program. Available at: http://www.hc-sc.gc.ca/fn-an/nutrition/ gras-trans-fats/tfa-age_tc-tm-eng.php. Accessed, July 31, 2009.

[27] AC Nielsen. Available at: http://ca.nielsen.com/site/ index.shtml Accessed: July 13, 2009.

[28] Ratnayake WMN, L'Abbe MR, Farnworth S, Dumais L, Gagnon C, Lampi B, Casey V, Mohottalage D, Rondeau I, Underhill L, Vigneault M, Lillycrop W, Meleta M, Wong L, Ng T, Gao Y, Kwong K, Chalouh S, Pantazopoulos P, Gunaratna H, Rahardja A, Blagden R, Roscoe V, Krakalovich T, Neumann G, Lombaert GA. 2009. Trans- fatty acids: Current contents in Canadian foods and estimated intake levels for the Canadian population. J. AOAC Int. 92:120

[29] AOAC International. AOAC Official Method 996.06. Fat (Total, Saturated, and Unsaturated) in foods, hydrolytic extraction gas chromatographic method,
Revised 2001. In: Official Methods of Analysis of AOAC International 18th Edition (Horwitz, W, ed.).

[30] Foodservice and Hospitality, Canada's Hospitality Business Magazine. 2008. The top 100 Report 2007.

[31] Statistics Canada. 2004. Canadian Community Health Survey - Cycle 2.2 on Nutrition. Available at: http://www.hc-sc.gc.ca/fn-an/alt_formats/hpfb-dgpsa/ pdf/pubs/cchs-escc_vol1-eng.pdf. Accessed: July 13, 2009.

[32] Health Canada. 2001. Canadian Nutrient File, version 2001 (electronic version) Available at: www.healthcanada.gc.ca/cnf

[33] Department of Statistics and Center for Agricultural and Rural Development, Iowa State University: A User's Guide to SIDE, Software for Intake Distribution Estimation Version 1.0. Technical Report 96-TR 30. Ames, IA. Iowa State University Statistical Laboratory, 1996. Available at: http://www.card.iastate.edu/publications/DBS/PDFFi les/96tr30.pdf

[34] Yeo D, Mantel H, Lin T-P. 1999. Bootstrap variances estimation for the National Population Health Survey. In 1999 proceedings of the Survey Research Methods Section, American Statistical Association, pp. 778-783.

[35] HDR Decision Economics Inc. 2009. Cost-Benefit Analysis of Reducing the Trans Fat Content of the Canadian Food Supply - Final Report

[36] Canadian Council of Food and Nutrition. 2008. Tracking Nutrition Trends VII.

[37] Garriguet D. 2004. Nutrition: Findings from the Canadian Community Health Survey. Overview of Canadians' Eating Habits. Statistics Canada. Available at: http://www.statcan.gc.ca/pub/82-620-m/82-620m2006002-eng.pdf. Accessed: July 13, 2009.

[38] Counil E, Dewailly E, Bjerregaard P, Julien P. 2008. Trans polar-fat: all Inuit are not equal. $\mathrm{Br} J \mathrm{Nutr}$. 100:703-706.

[39] Piché LA, Garcia AC. 2001. Factors influencing foodbuying practices of grocery shoppers in London, Ontario. Can J Diet Pract Res. 62:199-202.

[40] Ricciuto L, Ip H, Tarasuk V. 2005. The relationship between price, amounts of saturated and trans fats, and nutrient content claims on margarines and oils. Can J Diet Pract Res 66:252-255.

[41] Ricciuto L, Lin K, Tarasuk V. 2009. A comparison of the fat composition and prices of margarines between 2002 and 2006, when new Canadian labelling regulations came into effect. Public Health Nutr. 12:1270-1275.

[42] Giskes K, Van Lenthe FJ, Brug J, Mackenbach JP, Turrell G. 2007. Socioeconomic inequalities in food purchasing: the contribution of respondent-perceived and actual (objectively measured) price and availability of foods. Prev. Med. 45:41-48.

[43] Travers KD. 1996. The social organization of nutritional inequities. Soc Sci. Med. 43:543-553 
[44] Statistics Canada. 2004. Ten Leading Causes of Death, Canada, 2004 and 2005. Available at: http://www.statcan.gc.ca/pub/84-215-x/2009000/tbl/ tbl1-eng.htm Accessed: July 13, 2009.

[45] Mozaffarian D, Abdollahi M, Campos H, Houshiarrad A, Willett WC. 2007. Consumption of trans fats and estimated effects on coronary heart disease in Iran. Eur J Clin Nutr.61 (8):1004-1010.
[46] Katan M. 2006. Regulation of trans fats: The gap, the Polder, and McDonald's French fries. Atherosclerosis Supplements 7 63-66.

[47] Food and Drug Administration (FDA). 2003. Food Labeling: Trans Fatty Acids in Nutrition Labeling, Nutrient Content Claims, and Health Claims, Food and Drug Administration (FDA) - Federal Register, Vol. 68, No. 133, Rules and Regulations 